\title{
Is rat-dam licking behavior regulated by pups' preputial gland secretion?
}

\author{
I. BROUETTE-LAHLOU, E. VERNET-MAURY, and J. CHANEL \\ Laboratoire de Physiologie Neurosensorielle, CNRS \\ Université Claude Bernard/Lyon, Villeurbanne, France
}

\begin{abstract}
Anogenital licking (AGL) is crucial for pups' survival; nonlicked pups cannot defecate, and they die. A cotton swab impregnated with anogenital smears was investigated and the odorous testbox containing it was sniffed by virgins and adult males as well as by dams. When the pups' heads were rubbed with anogenital smears and the perineal area cleaned, the dams licked only the heads. The same results were obtained with a lipidic extract from pups' preputial glands. Chromatographic analysis of that extract showed the same peaks as those obtained from anogenital smears and thus confirmed preputial glands as the source of the attractant. Without pups' preputial glands, AGL did not disappear, but it was disrupted. Some pups were never licked, and died; median licking time increased from 14.5 (control) to 20 sec. Preputial secretions were designated as a regulating factor of AGL. What may induce AGL in the absence of pups' preputial gland secretion is discussed.
\end{abstract}

Immediately after parturition, cues from pups are required to ensure continuation of the maternal behavior that has been initiated prepartum by hormonal stimulation (primarily estrogens; see Rosenblatt, Siegel, \& Mayer, 1979). In contrast to the estrogens that clearly play a role in the prepartum period, the stimuli from pups that maintain maternal behavior in the postpartum period are less well understood. Among these, olfactory cues are the most important, as has been demonstrated by many experimental results (Lévy \& Poindron, 1984; Mena \& Grosvenor, 1971; Noirot, 1970; Rosenblatt et al., 1979). Olfactory cues are strongly involved in a particular component of maternal behavior: anogenital licking (henceforth AGL; see Charton, Adrien, \& Cosnier, 1971).

In the case of ungulates, it is well known (Poindron, 1983) that ewes lick their lambs right after parturition. Keverne, Lévy, Poindron, and Lindsay (1983) have shown that vaginal stimulation and amniotic fluid are determinants of this behavior. In the rat, the eliciting factor is not yet known. Nevertheless, in the first 3 weeks of the rat pup's life, AGL is essential; it stimulates reflexive defecation and urination (Diaz, Moore, Petracca, Schacher, \& Stamper, 1981; Henning, 1981; Moore, 1981; Rosenblatt et al., 1979). Various other functions of AGL have been demonstrated. According to Lent (1974) and Leuthold (1977), it serves the hygienic functions of cleaning the pup's perineal area and reducing conspicuousness to predators.

Furthermore, just as pups obtain water, electrolytes, and their other dietary requirements from mother's milk, mothers reclaim water and electrolytes from pup urine,

Correspondence should be addressed to Evelyne Vernet-Maury, Laboratoire de Physiologie Neurosensorielle, CNRS, Universite Claude Bernard/Lyon, F-69622 Villeurbanne cedex, France. maintaining the homeostasis of their body fluid. The ingestion of pup urine by the dam via AGL significantly attenuates the maternal loss of these two resources (Gubernick \& Alberts, 1983). Finally, Moore (1981, 1982, 1985), Birke and Sadler (1985), and Deviterne, Desor, and Messaoudi (1987) have established that anogenital stimulation contributes to sexual differentiation in rats.

Dam AGL plays an important part in the onset of maternal behavior, as has been shown by Szechtman, Rosenblatt, Siegel, and Komisaruk (1977). These authors not only confirmed tail-pinching as a facilitatory factor in the onset of maternal behavior, but also showed that the behavioral effects of tail-pinching stimulation outlast the pinching period and are cumulative. Their fundamental point was that females that licked pups more vigorously following tail-pinching tended to become maternal sooner. Sherman (1975) has reported that AGL is the first pattern occurring at the onset of maternal behavior; virgins that had their tails pinched only licked the pups when first exposed to them; but lactating females that were already exhibiting maternal behavior tended to pick up and carry pups in response to tail pinching. This experiment brought clearly to the fore the importance of AGL in maternal behavior. Further proof was contributed by Stern (1983), who observed that a few minutes or seconds of pup licking during priming hastened the subsequent onset of full maternal behavior during concaveation in nulliparous female rats. Moreover, mouse pups with cream on the perineal area are not recognized by the dam (Chantrey \& Jenkins, 1982). In these experiments, the authors generally did not mention whether all parts of the pup's body or specifically the anogenital area are licked by the dam. However, we previously showed that $88 \%$ of total licking time is spent licking the pup's anogenital area (Brouette-Lahlou, 1989). 
AGL was analyzed by Moore (1981), who pointed out that dam rats interact differently with male and female offspring. These dams spontaneously direct more licking to male pups, perhaps because of a greater concentration of testosterone or one of its metabolites in the urine that males secrete perineally (Moore, 1985).

On the other hand, in a feedback system, pups consume the dam's feces when they are 17 days old. This ingestion protects the young against necrotizing enterocolitis (Moltz \& Lee, 1981) and promotes maturation of pups' brains (Lee \& Moltz, 1984; Schumacher \& Moltz, 1985).

An attracting substance was found in the rat pup's anogenital area by Charton et al. (1971). They hypothesized that a chemical agent activates and focalizes the act of licking in the perineal region: animals preferred water containing anogenital smears as opposed to distilled water. Was the attractant gustatory and/or olfactory? The question has yet to be answered.

The experiments reported below were designed to identify this substance, because to do so would provide an important link in the understanding of maternal behavior. We had therefore first to find out what stimuli induced pup licking: olfactory stimuli, gustatory stimuli, or both (Experiments 1 and 2)? Second, we had to identify the active part of anogenital smears (Experiments 3, 4, and 5); and last, we had to define the role of the active part of anogenital smears in licking behavior (Experiments 6 and 7).

\section{EXPERIMENT 1}

The first point was to quantify the attractiveness of the perineal smears for different groups of rats at different hormonal stages.

\section{Method}

Subjects. We used Wistar rats housed individually in Perspex $39 \times 19 \times 18 \mathrm{~cm}$ observation cages; the floor of these was covered with wood shavings. The animals were maintained on the natural light:dark cycle of May and June (lights on around $0500 \mathrm{~h}$ and off around $1900 \mathrm{~h}$ ) and had free access to food and water. Twenty lactating females $(225 \mathrm{~g})$ were observed intermittently from $8 \mathrm{a} . \mathrm{m}$. to 1 p.m., a time corresponding to the peak of maternal behavior, according to Ader and Grota (1970). The dams were observed 5 days postpartum. Twenty males $(450 \mathrm{~g}), 20$ virgins $(170 \mathrm{~g})$, and 20 nonlactating females $(265 \mathrm{~g})$ that had previously raised litters were observed under dim illumination during the 1st hour of the daily evening dark period. Each litter was culled to 4 males and 4 females when possible.

Apparatus and Stimuli. We obtained perineal secretions (paying attention not to include urine and feces) by gently stroking the genitalia of 5-day-old pups (males or females) with cotton swabs impregnated with distilled water. We stopped stroking before urine and/or feces were released. Cotton swabs were presented to each test animal in a dual-choice apparatus identical to its home cage; it was permitted to visit the experimental cage 1 day before the test so it could leave traces of its odorants in the cage. Thirty minutes after the experimental animal entered the apparatus, two perforated boxes ( $50 \mathrm{~mm}$ diameter, $30 \mathrm{~mm}$ deep, with holes $6 \mathrm{~mm}$ in diameter) containing either anogenital smear odor or distilled water were fixed to the opposite sides of the container; the positions of the boxes were randomly assigned for each animal test. The time the rat spent sniffing near each box was cumulatively recorded on stopwatches in a 3-min observation period. Each rat was observed over one such period. Characteristic sniffing behavior is observed when the dam's nose is about $5 \mathrm{~mm}$ from the perforated cover of the box containing smears and when vibrissae movements can be seen.

\section{Results and Discussion}

The results are plotted in Figure 1. The box containing smears was sniffed significantly more than the control box by all groups of rats (Wilcoxon test, $p<.005$ ). Surprisingly, the time spent sniffing the odorous box by males and virgin females was greater than that spent by lactating females. Medians (semi-interquartile ranges) for the sniffing times were respectively: lactating females, $16 \mathrm{sec}(8)$; nonlactating females, $19.5 \mathrm{sec}(5)$; males, $29 \sec (6,5)$; virgins, $30 \mathrm{sec}(9)$. The four groups of rats were significantly different (Kruskal-Wallis Test, $H=$ $11.1, p=.00094)$. Because no differences were observed between (1) males and virgins and (2) lactating or not lactating females, two new groups were then formed and compared. The males and virgins sniffed the smears significantly more than did the other females (Mann-Whitney $U$ test, $Z=3.2, p=.0007)$. This result agrees with the Fleming and Rosenblatt (1974) report of a greater amount of licking in virgin females than in lactating females.

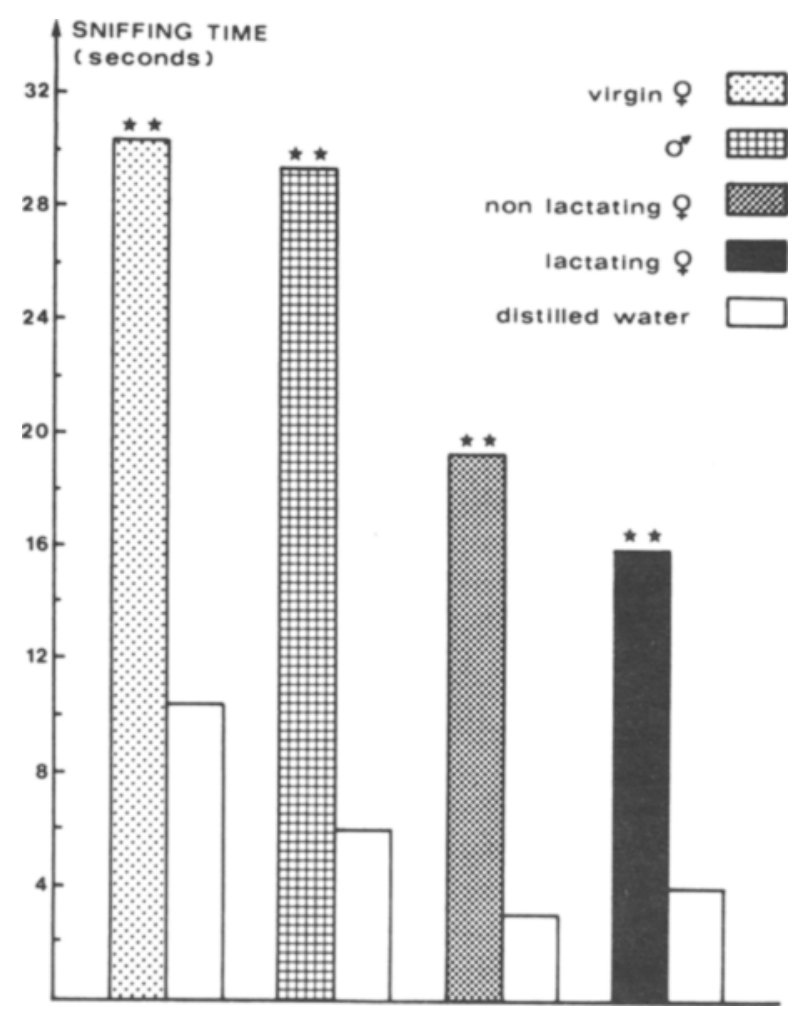

Figure 1. Median snifring time: Responses of different groups of rats (virgin females, males, nonlactating females, lactating females) to pups' perigenital odor versus blank (distilled water) in a 3-min test. All groups of rats are significantly attracted by perigenital odor (Wilcoxon test, $p<$.005). 
Dam's shorter sniffing times might be explained by the fact that they already knew how to identify pups with the help of other stimuli; after sniffing the odor box, they realized that it contained no pups.

This experiment, along with the results of Charton et al. (1971), clearly demonstrates the involvement of an olfactory cue in a particular component of the maternal behavior in rats' perigenital licking. Independently of their hormonal stage, all groups of rats could detect the pup's anogenital odor and were attracted by this stimulus.

\section{EXPERIMENT 2}

This experiment was designed to reveal the meaning of the olfactory signal to the dam in particular. Specifically, is the dam attracted by a particular region or a particular odor?

\section{Method}

Subjects. The subjects were the 20 lactating primiparous females used in Experiment 1. Otherwise, the subjects' conditions were the same as those in Experiment 1. Each dam was observed once.

Procedure. Experiment 2 took place after the dam had been returned to its home cage at the end of Experiment 1. All pups of each litter, except for the 3 used in the experiment, were kept in their home cage.

The heads of 2 5-day-old pups (male or female, indifferently) of each litter were rubbed with anogenital smears (see Experiment 1), and their anogenital areas were cleaned. Each experimental pup was marked differently with potassium permanganate. The dams ( 5 days postpartum) were left with the remaining pups. These experiments were performed blind, with one experimenter who marked the pups and another who made behavioral observations. The 2 experimental pups (Pups 1 and 3) and 1 control (Pup 2)-with the anogenital area and head uncleaned-were added one at a time to the test cages, which were identical to those used in Experiment 1, and they were placed approximately $15 \mathrm{~cm}$ from the nest (the pups' numbers denote their position in the sequence). No urine was placed on the head of control pups, because our tested samplings concerned only preputial secretions, not urine. Beaver (1960) demonstrated that the preputial gland excretory duct does not connect with the terminal urethra as had previously been thought. The time interval between introducing 1 pup and the next was around $30 \mathrm{sec}$, just as, in the nest, the dam licks the pups one after another. After the introduction of 3 pups, a 5 -min observation began, during which all licking of the anogenital region was noted.

\section{Results and Discussion}

The dams typically retrieved the pups quickly. Sixteen out of 20 experimental pups presented first in the sequence and 14 out of 20 pups presented third were licked on the head $(N=20, x=4, p=.006 ; N=20, x=6$, $p=.05$; binomial test). The dams sniffed but did not lick anogenital regions. However they licked the anogenital regions of the uncleaned, control pups, which were presented second. These results are in agreement with Moore's (1981) observations that a drop of urine placed on the head of a pup elicited licking; the urine sample obtained by rubbing the pup's genitalia may yet contain anogenital smears.
Consequently, the dam can distinguish the anogenital odor from the other odors emitted by pups. From these results, it appeared that anogenital odor, not anogenital area, primarily determined perineal licking behavior.

\section{EXPERIMENT 3}

The next point was to locate where the odorous substance was produced. Preputial glands were suspected, because, in the rat, preputial ducts open in the area where the attracting smears were obtained. Two white preputial ducts are seen just under the skin in neonates. These glands, which were described by Beaver (1960), are also present in adult rats. Their function is related to sexual behavior (Gawienowski, Orsulak, Stacewiz-Sapuntzakis, $\&$ Pratt, 1976): preputial secretions enable adult rats to determine whether the odor originates from a male or a female adult rat. They are called bulli vestibuli in females and preputial glands in males. For the sake of simplicity, we will use the term preputial gland for male, female, and newborn rats.

\section{Method}

Subjects. The rats were 20 lactating females that had not been used in the first two experiments.

Procedure. Observations were made when the pups were 5 days old. Lactating females were presented with perforated boxes in a dual-choice apparatus, as in Experiment 1.

Stimulus. The source of odorants was the product of the preputial gland obtained by dissolving the preputial secretions of 5-dayold pups (male and female) in a lipidic solvent (ether or dichloromethane), for it was suspected that the secretions were lipidic in nature (Vernet-Maury \& Brouette-Lahlou, 1985). Before sampling, pups were isolated and kept warm for $.5 \mathrm{~h}$. We used a sterilized syringe (diameter: $0.5 \mathrm{~mm}$ ) to take a secretion sample from the pups, introducing the needle in the opening of the preputial glands. From 5 pups, approximately $0.1 \mathrm{mg}$ of whole preputial secretion was obtained. The preputial secretion dissolved in the solvent was then spread on cotton swabs presented to the dams in boxes as in Experiment 1. Each dam had to choose between the odor box or the solvent only (dual-choice apparatus). The control box was "labeled" with evaporated solvent. Sniffing times were recorded on stopwatches during a 3-min observation period. The results from this experiment were compared with those concerning the lactating females of Experiment 1.

\section{Results and Discussion}

As can be seen in Figure 2, dams spent much more time sniffing the odorous box (preputial smears or preputial extracts) than did the control (distilled water or solvent). No difference in the amount of sniffing was observed as a function of the solvent used for lipid extraction ( $p=$ .345). Thus, the sniffing times of preputial secretions extracted through both solvents (Experiment 2) were compared with the sniffing times of anogenital secretions in Experiment 1. The comparison revealed no difference (Mann-Whitney $U$ test: $U=149, n 1=n 2=20$, n.s.). These results allowed us to confirm that the preputial gland was the origin of the anogenital area secretion. 


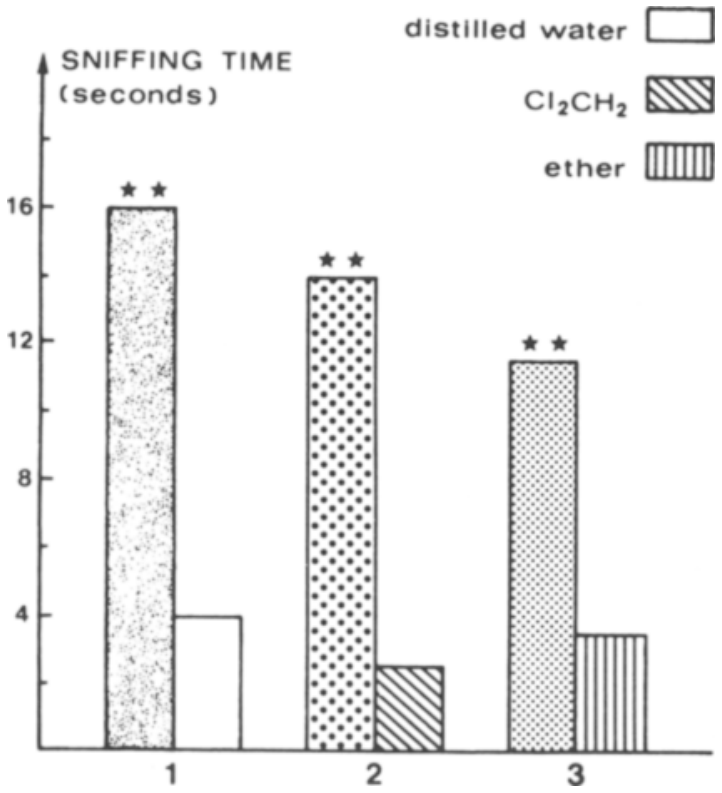

Figure 2. Median snifring time: Lactating females' responses to pups' anogenital smears (bar 1: results from Experiment 1) and preputial secretion extracts (hars 2 and 3: results from Experiment 3) in a 3-min test. For bars 2 and 3, the taller bar is for extract plus evaporated solvent; the shorter is for evaporated solvent alone.

\section{EXPERIMENT 4}

Experiment 2 was replicated to confirm that preputial gland was the origin of the anogenital odor.

\section{Method}

Subjects. The 20 lactating females of Experiment 3 were observed on Day 5 after parturition.

Procedure. Preputial gland secretion dissolved in dichloromethane was spread on 25 -day-old pups' heads according to the same procedure as in Experiment 2. Immediately after evaporation of the solvent, stimulus pups were added one at a time to the dam's cage as described in Experiment 2. The control pup was anogenitalarea-and head-untreated.

\section{Results and Discussion}

Fifteen out of 20 experimental pups presented first in the sequence (binomial test, $n=20, x=5, p=.006$ ) and 14 out of 20 experimental pups presented third ( $n=20, x=6, p=.05$ ) were licked on the head region by the dam. No control pup was licked in the head area. From Experiments 3 and 4, preputial gland secretions were strongly suspected to be the source of the attractant.

\section{EXPERIMENT 5}

To confirm that the preputial gland was the source of the attractant, gas chromatographic peaks of anogenital smears and preputial gland secretions were compared.

\section{Method}

Subjects. A total of 160 pups (males and females) from different litters were used. The pups were from just born to 18 days old.
Sampling procedure. Anogenital smear samples were obtained by gently stroking the genitalia of 110 pups (males and females) with a glass rod; preputial secretion samples were obtained using a special syringe (see Experiment 3 ) introduced into the preputial gland orifice of 50 pups (males and females).

Samples were extracted with dichloromethane or ether, and the extracts, sealed in glass tubes, were kept in a deep freeze $\left(-10^{\circ} \mathrm{C}\right)$ until used.

Chromatographic procedure. These extracts were identified with a chromatographic procedure; an Intersmat IGC 120 DFB with flame-ionization detector was used. It was lined with an SE30 column. The carrier gas was nitrogen. The analysis was temperature programmed at $230^{\circ} \mathrm{C}$, the detector at $220^{\circ} \mathrm{C}$, and injector at $210^{\circ} \mathrm{C}$. Four microliters of each extract were gas chromatographed. Peaks were identified using their retention time.

\section{Results and Discussion}

After the solvent peaks (Figure 3), two peaks were shown with a retention time of respectively 8 and $12 \mathrm{~min}$ in the anogenital smears extract (A) and in the preputial gland extract (B). The higher peaks observed in chromatogram $B$ may be explained by the preputial glands being the source of the odorants. We needed 100 pups to ob-

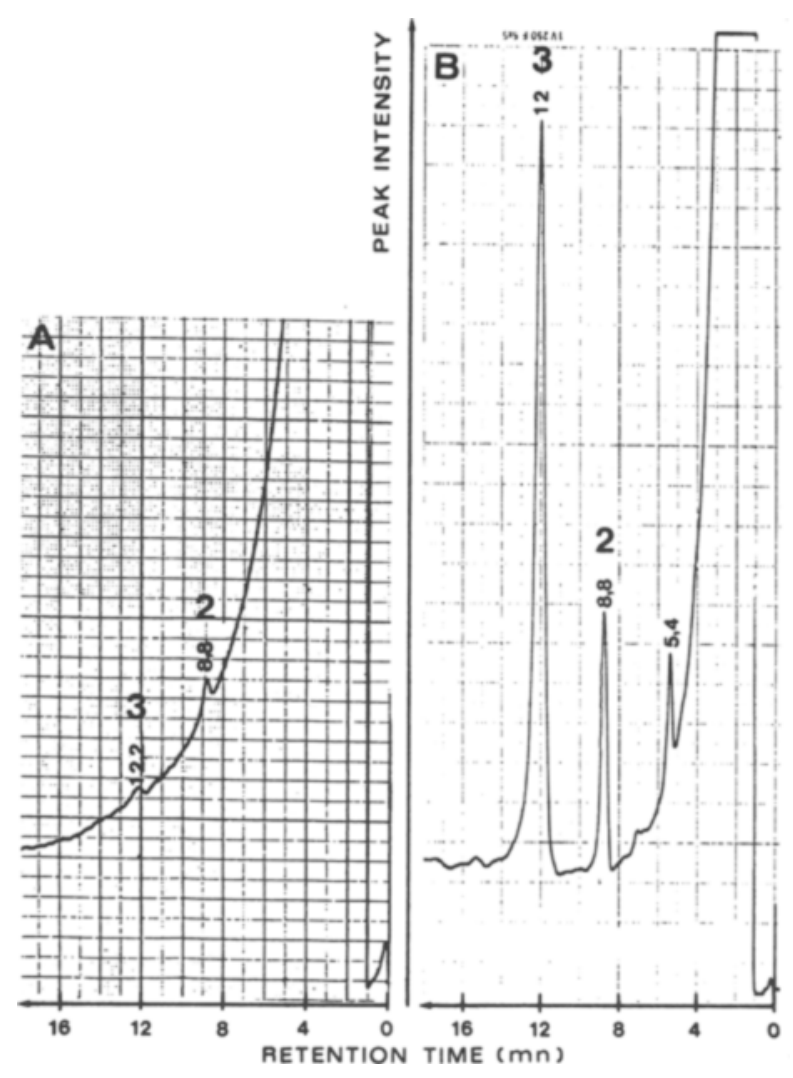

Figure 3. Chromatographic comparison of the sources of pups' odorant (flame-ionization detector). (A) Glandular anogenital smear samples from 110 pups. (B) Preputial glandular secretion from 50 male and female pups. At the top of the different peaks are plotted their exact retention time. An SE 30 column was used. Oven temperature was $230^{\circ} \mathrm{C}$ and detector one $220^{\circ} \mathrm{C}$. Nitrogen pressure was from 2.8 to 3 bars. Peak 1, not labeled in Figure 3A, corresponds to the peak of the solvent (retention time from $\theta$ to about $6 \mathrm{~min}$ ). 
tain a $2.5-\mathrm{mm}$ peak in chromatogram $A$, and only 40 pups to obtain a $4.5-\mathrm{cm}$ peak in chromatogram $B$. The same peaks were found in the two different extracts. This chromatographic comparison provides a new argument to confirm the preputial glands as the source of AGL odorants.

The pup's preputial glands have been shown to be the source of anogenital odor, as witnessed by the maternal responsiveness to the preputial secretion odor. Moreover, the lactating females responded to one "specific odor," not to one "specific area" of the pup.

Thus, an odorant stimulus was produced by the preputial glands, and it plays a role in dam's AGL. The new question was then: Does it induce AGL?

\section{EXPERIMENT 6}

This experiment was designed to determine the action of the preputial gland secretions in AGL behavior. The preputial glands of pups were ablated (preputialectomy), and the dams' were responses observed.

\section{Method}

Subjects. Thirty-two primiparous lactating females were observed. The pups of 20 lactating dams were preputialectomized when they were 6 days old. The pups of 6 dams were sham-operated, and the pups of 6 other dams served as controls.

Procedure. Preputialectomy was carried out, under either anesthesia, 6 days after birth. A pane of skin about $1 \mathrm{~cm}^{2}$ was cut on three sides, $1 \mathrm{~cm}$ above the perineal area, to protect this area from licking by the dam. The preputial glands lying just under the skin were easily cut away. The incision was performed opposite the anogenital area ( $1 \mathrm{~cm}$ away) so that the dam's wound-cleaning movements could be easily distinguished from AGL (see below). All the pups from 20 lactating females were preputialectomized. In the shamoperated animals, the skin incision occurred under ether anesthesia, but the preputial glands were not removed. The treated pups were kept warm and placed back in the home cage as soon as the anesthesia was off and the pups' breath became regular again. AGL time was recorded during the day on Days 7,9, and 11 , the first observations beginning a day after surgery. A minimum of 20 AGL bouts were recorded for purposes of statistical analysis. The median licking time per bout was calculated. AGL is easily recognized by orientation of the dam's head between the pups' hindlegs and by a typical "vibration" of the mother's head and snout.

\section{Results and Discussion}

The main observation was inhomogenous distribution of AGL toward the different pups of the litter: some pups were licked, some were not. Paradoxically, when AGL occurred, its duration was longer toward preputialectomized pups than toward control and sham-operated pups. The results are plotted in the right half of Table 1. A KruskalWallis test pointed out significant differences between the three treatments on Days 7, 9, and 11 (Day 7, $H=17.7$, $p=.001$; Day 9, $H=15.27, p<.001$; Day 11, $H=$ $21.03, p<.001)$. The Mann-Whitney $U$ test allowed us to separate preputialectomized pups from sham-operated and intact pups (on Day 7, for preputialectomized vs. shamoperated, $U=80 ; Z=3.24, p<.001$, and for preputialectomized vs. intact, $U=55, Z=-3.92, p<$ .0001 ; on Day 9 , for preputialectomized vs. sham-operated, $U=66.5, Z=3.61, p<.001$, and for preputialectomized vs. intact, $U=101, Z=2.67, p<.01$; on Day 11 , for preputialectomized vs. sham-operated, $U=$ $36.5, Z=4.42, p<.0001$, and for preputialectomized vs. intact, $U=74, Z=3.40, p<.001$ ). Conversely, AGL time with sham-operated pups was not statistically different from that with controls (Day 7, $U=173, Z=$ 0.73 , n.s.; Day 9, $U=139.5, Z=1.63$, n.s.; Day 11 , $U=182.5, Z=0.47$, n.s.). Thus, despite the absence of preputial secretions, AGL behavior was not suppressed. Surgery itself had no effect on AGL time (see Figure 4, right). This was not surprising, because AGL was directed at an area different from that with the surgical wound and, second, because AGL was different from the woundcleaning movement as explained before; so these two patterns cannot be confounded.

Some preputialectomized pups $(19 \%)$ died of swollen bellies due to big, full intestines. We hypothesized that these swollen-bellied pups had not been licked-or were licked less-and could not defecate. Moreover, the mechanisms for regulating food intake during the suckling period are immature; pups aged 14 days and younger, if given an unlimited supply of milk, will continue ingestion until their stomachs are so distended that they can barely walk (Henning, 1981).

\section{EXPERIMENT 7}

Dams may have learned licking behavior during the 6 days before preputialectomy. Preputialectomy carried out at parturition will allow us to eliminate the learning phenomenon.

Table 1

Median (with Semi-Interquartile Ranges) Anogenital Licking Time (in Seconds) of Lactating Females in a Daily Observation Schedule Toward Preputialectomized Pups, Sham-Operated Pups, and Control Pups

\begin{tabular}{|c|c|c|c|c|c|c|c|c|c|c|c|c|c|c|c|c|}
\hline \multirow[b]{3}{*}{ Days Postpartum } & \multicolumn{8}{|c|}{ Preputialectomy at Birth } & & \multicolumn{7}{|c|}{ Preputialectomy 6 Days Postpartum } \\
\hline & \multicolumn{2}{|c|}{1} & & \multicolumn{2}{|c|}{3} & & \multicolumn{2}{|c|}{5} & & \multicolumn{2}{|c|}{7} & \multicolumn{2}{|c|}{9} & & \multicolumn{2}{|c|}{11} \\
\hline & $M$ & $S R$ & & $M$ & $S R$ & & $M$ & $S R$ & & $M$ & $S R$ & $M$ & $S R$ & & $M$ & $S R$ \\
\hline Preputialectomized pups & 21 & $3.2:$ & & 18,5 & $2.5:$ & & 20,5 & 6.7 & & 24,5 & $4:$ & 22 & $4.5 *$ & & 20,5 & $6.7:]$ \\
\hline Sham-operated pups & 14 & $\begin{array}{c}1.7 \\
\text { n.s. }\end{array}$ & : & 14,5 & $\begin{array}{c}1.2 \\
\text { n.s. }\end{array}$ & * & 14 & $\begin{array}{c}2.2 \\
\text { n.s. }\end{array}$ & * & 14,5 & $\begin{array}{c}2.5 \\
\text { n.s. }\end{array}$ & 13 & $\begin{array}{r}3.2 \\
\text { n.s. }\end{array}$ & * & 14 & $\begin{array}{c}1.5 \\
\text { n.s. }\end{array}$ \\
\hline Control pups & 14 & 2 & ] & 15 & 3 & & 14,5 & $2.7]$ & & 14 & $2.2]$ & 14,5 & $4.2]$ & & 13,5 & $3^{0 .}$ \\
\hline
\end{tabular}

Note-Mann-Whitney $U$ test: $" p<.05, * p<.01, \quad ; p<.001, \quad ; p<.0001$. 


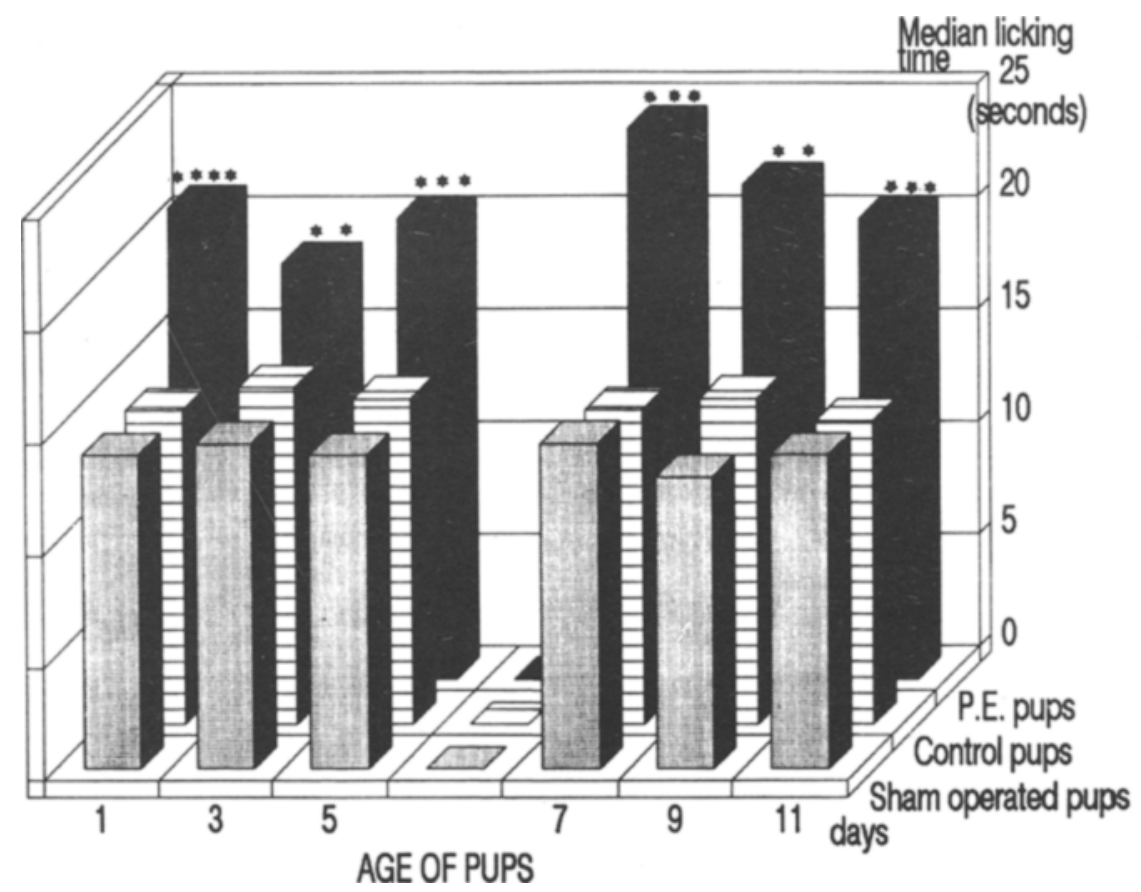

Figure 4. Median licking time: Dams' responses to preputialectomized (P.E.) pups, sham-operated pups, or control pups in Experiments 6 and 7. Results are plotted according to the date of preputialectomy: just at birth (licking time was recorded on Day 1,3 , or 5) or 6 days after birth (licking time was recorded on Days, 7, 9, and 11).

\section{Method}

Subjects. Thirty-two females were mated and observed after their pups' treatment at birth. The pups from 6 dams were kept intact; the pups from 6 other dams were sham-operated, and the pups from 20 dams were preputialectomized.

Procedure. The pups were observed on Days 1,3, and 5 after birth. Licking time was monitored as in Experiment 6.

Surgery was practiced as described before (Experiment 6), but it took place just after birth, before the pups had been licked by the dam.

\section{Results and Discussion}

Preputialectomized pups were licked more than intact or sham-operated ones (Table 1, left). The Kruskal-Wallis test revealed a difference on Days 1,3 , and 5 (Day 1; $H=25.80, p<.001$; Day 3, $H=10.16, .001<p<$ .01 ; Day $5, H=16.99, p<.001$ ). A Mann-Whitney $U$ test revealed only differences between the preputialectomized pups and the two control groups (on Day 1, for preputialectomized vs. sham-operated, $U=34, Z=4.49$, $p<.00003$; for preputialectomized vs. intact, $U=44.5$, $Z=4.20, p<.0003$; and for sham-operated vs. intact, $U=171, Z=0.78$, n.s.; on Day 3 , for preputialectomized vs. sham-operated, $U=85, Z=3.11, p<.001$; for preputialectomized vs. intact, $U=118.5, Z=2.20$, $p<.01$; and for sham-operated vs. intact, $U=171.5$, $Z=0.77$, n.s.; on Day 5 , for preputialectomized vs. sham-operated, $U=60.5, Z=3.77, p<.001$; for preputialectomized vs. intact, $U=77.5, Z=3.31$, $p<.001$; and for sham-operated vs. intact, $U=189.5$,
$Z=0.28$, n.s.). Surgery itself did not affect licking time, which was around $14 \mathrm{sec}$ for the control intact pups as well as the sham-operated pups, the medians (semiinterquartile ranges) on Days 1,3 , and 5 were, respectively: 14 (1.7), 15 (3), and 14.5 (2.7), and 14 (1.7), 14.5 (1.2), and 14 (2.2) (Figure 4, left). Although dam AGL was still carried out, it seemed disorganized: some pups were never licked, others were licked and licked again, and the latter tried to leave the dam, using their hindlegs.

The main result of this preputialectomy was a greater number of dead pups: $35 \%$ mortality. None of the 48 $(8 \times 6)$ sham-operated pups from 6 dams died; mortality was due only to preputialectomy.

\section{GENERAL DISCUSSION}

Chemical stimulation develops into the mother-young bond. The newborn secretes a substance that is very attractive to the dam. For males, virgins, and nonlactating females, the function of the attraction has to be defined. On the basis of observations of adults (Jakubowski \& Terkel, 1985), we hypothesized that the aggressiveness of the male is slight at birth time; the pups' survival may be ensured by this attracting odor.

In agreement with a recent statement, AGL odor activates and focalizes the act of licking in the perineal region (Cosnier, 1984). Furthermore, our results established indubitably that this secretion has a regulating function as 
regards AGL. Preputial secretions allow the dam to distinguish licked pups from nonlicked ones and to regulate licking time; without these secretions, AGL was disorganized. Some pups were never licked, or were licked less; they could not defecate, and so they died. The greater mortality observed in pups may be due to this phenomenon. The effects of preputial gland ablation enable us to claim that the stimulus from preputial glands did not induce AGL but regulated it.

The odorant stimulation from preputial glands is an important stimulus for maternal behavior; many pups died without it. Is another factor responsible for the observed results? In the ewe, amniotic fluid has been shown to be an important factor in the onset of maternal behavior (Levy \& Poindron, 1984). In the present experiments, the absence of amniotic fluid could seem to have disrupted the regulation of AGL, but our 1990 results rule this out (Brouette-Lahlou \& Vernet-Maury, in press).

Moore and Samonte (1986) verified that the "neonatal preputial gland is a source of chemosignals that are attractive to dams and that are used by dams to identify [the] sex of [the] pup" in accordance with our first results (Vernet-Maury, Brouette-Lahlou, \& Chanel, 1987); compounds isolated chromatographically from preputial gland secretion may explain why male pups are licked longer than females.

After preputialectomy at birth or when pups are 6 days old, AGL duration is significantly enhanced. A previous work (Charton et al., 1971) demonstrated that collodion placed over the pup's anogenital region reduces AGL duration, probably because collodion forms a physical block owing to its tough constitution. Perhaps a small quantity of preputial secretion is exuded through collodion, which would explain the reduced AGL duration. AGL behavior is disorganized after pups' preputialectomy; but it is still present, and each AGL duration sequence is enhanced. Pups' skin is softer than collodion, and AGL behavior is not disturbed.

So the main question to be asked is, "What stimuli induce AGL in the dam?" Defecation in pups is produced by the dam's AGL. During licking, the dam may perceive a specific odor or flavor associated with subsequent urination and defecation by pups. Sniffing and ingestion of preputial secretion-odor or flavor-could be associated with the feces-ingesting behavior necessary to the steady state of the bacterian gut in the dam as well as in the pups (Moltz \& Lee, 1981). In this way, one form of motivation to detect and ingest preputial secretion could be produced in the dam; this might explain the increasing duration of AGL bouts after pups' preputialectomy.

\section{REFERENCES}

ADER, R., GROTA, J. (1970). Rhythmicity of the maternal behavior in Rattus norvegicus. Animal Behaviour, 18, 144-150.

BeAVER, D. L. (1960). A re-evaluation of the rat preputial gland as a "dicrine" organ from the standpoint of its morphology, histochemistry and physiology. Journal of Experimental Zoology, 143, 153-173.

BirKE, L. I. A., SADLER, D. (1985). Maternal behavior in rats and the effects of neonatal progestins given to the pups. Developmental Psychobiology, 18, 467-475.

BrouetTe-LAhLoU, I. (1989). Le ciblage et la régulation des comportements: Une fonction nouvelle des phéromones. Thèse de doctorat, Mention Neurosciences, Universite Lyon I.

Brouette-Lahlou, I., \& Vernet-Maury, E. (in press). Amniotic fluid and dodecyl propionate pheromone: Influence on the onset and regulation of maternal anogenital licking in the rat. In D. W. MacDonald, D. Muller-Schwarze, \& S. Natynczuk (Eds.), Chemical signals in vertebrates: $V$. Oxford, U.K.: Oxford University Press.

Chantrey, F. D., Jenkins, B. A. B. (1982). Sensory processes in the discrimination of pups by female mice (mus musculus). Animal Behaviour, 30, 881-885.

Charton, D., Adrien, J., Cosnier, J. (1971). Declencheurs chimiques du comportement de léchage des petits par la ratte parturiente. Revue du Comportement Animal, 5, 89-94.

CosNier, J. (1984). Progress in interaction models. Progress in Reproductive Biology \& Medicine, 11, 1-13.

Deviterne, D., Desor, D., \& Messaoud, M. (1987). Discrimination maternelle des jeunes rats: Sexe et développement précoce comme facteurs possibles. Bulletin SFECA, 2, 247-255.

Diaz, J., Moore, E., Petracca, F., Schacher, J., \& Stamper, C. (1981). Artificial rearing of preweanling rats: The effectiveness of direct intragastric feeding. Physiology \& Behavior, 27, 1103-1105.

Fleming, A., Rosenblatt, J. S. (1974). Maternal behavior in the virgin and lactating rat. Journal of Comparative Psychology, 86, 957-972.

Gawienowski, A. M., Orsulak, P. J., Stacewicz-Sapuntzakis, M., \& Pratt, J. I., JR. (1976). Attractant effect of female preputial gland extracts on the male rat. Psychoneuroendocrinology, 1, 411-418.

GUBERNiCK, D. J., \& ALBERTS, J. R. (1983). Maternal licking of young: Resource exchange and proximate controls. Physiology \& Behavior, 31, 593-601.

HeNning, S. J. (1981). Postnatal development: Coordination of feeding, digestion and metabolism. American Joumal of Physiology, 241, G199-214.

JakUBOWSKI, M., \& Terkel, J. (1985). Transition from pup killing to parental behavior in male and virgin female Albino rats. Physiology \& Behavior, 34, 683-686.

Keverne, E. B., Lévy, F., Poindron, P., Lindsay, D. R. (1983). Vaginal stimulation: An important determinant of maternal bonding in sheep. Science, 219, 81-83.

LEE, T. M., MOLTZ, H. (1984). The maternal pheromone and brain development in the preweanling rat. Physiology \& Behavior, 33, 385-390.

LENT, P. C. (1974). Mother-infant relationships in ungulates. In V. Geist \& F. Walther (Eds.), The behaviour of ungulates and its relation to management (Vol. 1, pp. 14-53). Morges, Switzerland: Unipub.

LeUThold, W. (1977). African ungulates. Berlin: Springer.

LÉvY, F., \&oINDron, P. (1984). Influence du liquide amniotique sur la manifestation du comportement maternel de la brebis parturiente. Biology of Behavior, 9, 271-278.

Meñ, P., Grosvenor, C. E. (1971). Release of prolactin in rats by exteroceptive stimulation: Sensory stimuli involved. Hormones \& Behavior, 2, 107-116.

MoLTZ, H., LEE, T. M. (1981). The maternal pheromone of the rat: Identify and functional significance. Physiology \& Behavior, 26, 301-306

Moore, C. L. (1981). An olfactory basis for maternal discrimination of sex of offspring in rats (Rattus norvegicus). Animal Behaviour, 29, 383-386.

MOORE, C. L. (1982). Maternal behavior of rats is affected by hormonal condition of pups. Journal of Comparative \& Physiological Psychology, 96, 123-129.

MOORE, C. L. (1985). Sex differences in urinary odors produced by young laboratory rats (Rattus norvegicus). Journal of Comparative Psychology, 99, 336-341.

MoORE, C. L., SAmonTe, B. (1986). Preputial glands of infant rats (Rattus norvegicus) provide chemosignals for maternal discrimination of sex. Journal of Comparative Psychology, 100, 76-80.

NoIRoT, E. (1970). Selective priming of maternal responses by audi- 
tory and olfactory cues from mouse pups. Developmental Psychobiology, 2, 273-276.

Poindron, P. (1983). Le comportement maternel de la brebis. La Recherche, 14, 538-541.

Rosenblatt, J. S., Siegel, H. I., \& Mayer, A. D. (1979). Progress in the study of maternal behavior in the rat: Hormonal, non-hormonal, sensory and developmental aspects. In J. S. Rosenblatt, R. A. Hinde, C. Beer, \& M. C. Busnel (Eds.), Advances in the study of behavior (Vol. 10, pp. 225-302). New York: Academic Press.

SChumacher, S. K., Moltz, H. (1985). Prolonged responsiveness to the matemal pheromone in the postweanling rat. Physiology \& Behavior, 34, 471-473.

SHERMAN, K. (1975). Tail-pinch induced maternal behavior. Unpublished master's thesis University of Pittsburgh.

STERN, J. M. (1983). Maternal behavior priming in virgin and Caesarean- delivered Long-Evans rats: Effects of brief contact or continuous exteroceptive pup stimulation. Physiology \& Behavior, 31, 757-763.

Szechtman, H., Rosendlatt, J. S., Siegel, H. I., * Komisaruk, B. R. (1977). Tail-pinch facilitated onset of maternal behavior in rats. Physiology \& Behavior, 19, 807-809.

Vernet-Maury, E., \& Brouette-Lahlou, I. (1985, August). Characterization and identification of the pheromone of the rat pup's preputial gland. Paper presented at the meeting of the 19th International Ethological Conference, Toulouse, France.

Vernet-Maury, E., Brouette-Lahlou, I., \& Chanel, J. (1987). Ontogenic analysis of the rat pup pheromone implicated in perigenital licking. Chemical Senses, 12, 186.

(Manuscript received November 26, 1989; revision accepted for publication November 23, 1990.) 